\title{
Avaliação mercadológica da borracha natural no Brasil
}

Danubia Rejane Silva Brito

Universidade Federal do Piauí, campus Professora Cinobelina Elvas, danubiabrito@hotmail.com

Waldeídes de Castro e Sousa

Universidade Federal do Piauí, campus Professora Cinobelina Elvas, waldeidescastro@hotmail.com

Joabel Raabe

Universidade Federal do Piauí, campus Professora Cinobelina Elvas, joabel@hotmail.com

Sidney Araujo Cordeiro

Universidade Federal do Piauí, campus Professora Cinobelina Elvas, sidneycordeiro@ufpi.edu.br

\section{Resumo}

Tendo em vista o grande consumo de borracha na indústria nacional e internacional, para diversas finalidades, este trabalho tem como objetivo, mostrar a importância da seringueira em âmbito comercial, dando enfoque nas oscilações de preço do principal produto proveniente desta espécie, com base em pesquisas mercadológicas encontradas na literatura, que abordam principalmente temas referentes à utilização racional de produtos naturais e a geração de renda proveniente destes. Mostrando de modo mais detalhado as características principais da fonte produtora de látex, e informações referentes às características gerais do produto, do processo produtivo, de mercado e também os desafios encontrados durante a produção e comercialização. Pode-se concluir que a adoção de medidas governamentais que incentivem o plantio da espécie que produz o látex e o investimento em pesquisas que combatam ou que venham a reduzir a incidência de pragas e doenças que atacam os seringais, seriam de fundamental importância para o controle destes plantios, bem como garantir qualidade e quantidade suficiente para atender o mercado consumidor.

Palavras-chave: Seringueira; Látex; Mercado.

\section{Evaluation of the market of natural rubber in Brazil}

\begin{abstract}
In view of the great rubber consumption in the national and international industry, for diverse purposes, this work has as objective, to show the importance of the seringueira in commercial scope, giving approach in the price fluctuations of the main product proceeding from this species, on the basis of found marketing research in literature, that mainly approaches referring subjects to the rational use of natural products and the generation of income proceeding from these. Showing in way more detailed the main characteristics of the producing latex source, and referring information to the general characteristics of the product, the productive process, market and also the challenges found during the production and commercialization. It can be concluded that the adoption of governmental measures that stimulate the plantation of the species that produces the latex and the Investment in research that fights or that they come to reduce the incidence of plagues and illnesses that attack you inject them, would be of basic importance for the control of these plants, as well as guaranteeing quality and amount enough to take care of the consuming market.
\end{abstract}

Keywords: Rubber tree; Latex; Market.

\section{Introdução}

Muitas espécies de vegetais tropicais apresentam borracha natural, especialmente na família das, no entanto, quase toda a produção mundial provém de uma espécie que tem sua origem no Brasil, Hevea brasiliensis, pertencente a esta família. Existe na floresta amazônica mais de 11 espécies de seringueira do gênero Hevea e todas muito parecidas entre si. Embora seja 
grande o número de espécies que por uma incisão na casca exsudam secreção de aspecto semelhante ao látex, somente algumas produzem quantidade e qualidade suficientes para exploração em bases econômicas (UFSC, 2001).

Segundo Bernardes et al. (2000), a história da produção da borracha natural brasileira mostra que o país desfrutou da condição de principal produtor e exportador mundial no final dos séculos XIX e início do século XX, passando a ser importador desta matéria prima a partir do começo dos anos cinquenta, do século passado. A utilização da borracha proveniente da seringueira é feita em diversos setores como, por exemplo: hospitalar/ farmacêutico, brinquedos, calçados, construção civil, maquinário agrícola e industrial e de autopeças.

A importância econômica e industrial da borracha natural fazia da seringueira uma árvore estratégica, sendo que sementes foram levadas pelos ingleses para serem plantadas em suas colônias na Ásia. Naqueles países a seringueira foi cultivada como uma espécie comercial, diferentemente do Brasil, onde estava em seu habitat natural. Portanto, enquanto o sistema de produção brasileiro era o extrativismo, o asiático se baseava na exploração comercial. Esse foi o principal fator de sucesso da produção de borracha na Ásia. Além desse aspecto agronômico, na Ásia não existia o fungo causador do maldas-folhas (Microcyclus ulei), que é uma das doenças mais comuns dos seringais - sobretudo na Amazônia (Borracha Natural, 2011).

Segundo Pereira et al. (2000) a partir da década de 60 foram elaborados no país planos ambiciosos para expandir a produção da borracha natural via cultivo da seringueira. Nos anos 70 e 80, o país investiu mais de US\$ 1,0 bilhão para viabilizar a cultura na Amazônia. Todavia, apenas os seringais formados fora da região Amazônica tornaram-se viáveis e fizeram crescer a produção nacional da borracha natural. De 1971 a 2004, a produção nacional de borracha natural aumentou $400 \%$, mas ainda é pequena quando comparada com a dos países asiáticos (CIFlorestas, 2011a).

O mercado de borracha natural está em ascensão. 0 principal consumidor do produto é o setor automobilístico, que atualmente importa do sudeste asiático a maior parte dessa matéria prima, já que o Brasil não dá conta de suprir a demanda (Seringueira, 2011).

O objetivo deste trabalho é mostrar a importância da seringueira em âmbito comercial, dando enfoque nas oscilações de preço do principal produto proveniente desta espécie, com base em pesquisas mercadológicas encontradas na literatura.

\section{MATERIAIS E MÉTODOS}

\subsection{Características gerais do produto}

Hevea brasiliensis ocorre na região amazônica, na margem de rios e lugares inundáveis da mata de terra firme, é uma planta lactescente de 20-30 m de altura, com tronco de 30$60 \mathrm{~cm}$ de diâmetro. Popularmente é conhecida como seringueira, seringa, seringa-verdadeira, cau-chu, árvore da borracha, seringueira-preta, seringueira branca (UFSC, 2011).

O látex produzido pela árvore é uma suspensão aquosa contendo 30 a $40 \%$ de sólidos em forma de partículas de borracha visíveis em ultramicroscópio. Com propriedades únicas entre os produtos naturais poliméricos, a borracha natural combina elasticidade, plasticidade, resistência ao desgaste (fricção), propriedades de isolamento elétrico e impermeabilidade à líquidos e gases (GONÇALVES et al., 1990).

As principais características da borracha natural que a tornam uma excelente matéria prima para setores tão variados são: elasticidade, flexibilidade, resistência à abrasão e à corrosão, impermeabilidade e fácil adesão a tecidos e ao aço (BORRACHA NATURAL, 2011).

O líquido, o látex, contém em suspensão um hidrocarboneto de elevado peso molecular. A borracha assim obtida é deformável como gesso e deverá ser processada para adquirir os requisitos necessários para ser utilizada em suas inúmeras aplicações. Por aquecimento e adição de ácido acético coagula formando uma massa gomosa que, depois de separada da água e outros produtos, denomina-se "borracha bruta”(UFSC, 2011).

A qualidade das borrachas naturais brasileiras é determinada, em primeira instância, através da inspeção visual, observando sua limpeza, cor, homogeneidade e defeitos. Depois, através de ensaios de laboratório específicos e normalizados são classificadas e comercializadas, com características padronizadas, exigidas pela norma ABNT-EB-1866 de 1988. Composição Química aproximada da borracha bruta: Hidrocarbonetos de borracha (93,7\%); Proteínas (2,2\%); Carboidratos (0,4\%); Lipídios naturais (2,4\%); Glicolipídios e Fosfolipídios (1,0\%); Materiais inorgânicos (0,2\%); outros (0,1\%)(UFSC, 2011).

\subsection{Método de pesquisa rápida}

A literatura sobre estudos que abordam aspectos técnicos e de mercado relacionados à extração de látex, proveniente de plantios de seringueira, mostra que diversos métodos de busca de informações e análise têm sido empregados, isoladamente ou de forma combinada. Entretanto, a diversidade de objetivos desses estudos e a 
multiplicidade de questões relacionadas com recursos físicos, financeiros e humanos, disponíveis para os estudos, impedem uma recomendação universal de opção metodológica para a busca de informações. Em geral, métodos mais precisos de coleta de informações são mais caros e demorados (IEL/CNA/SEBRAE, 2000).

Assim, segundo essas instituições, os objetivos do estudo, sua abrangência e a limitação do período de execução, optou-se por utilizar a metodologia denominada "pesquisa rápida". A exemplo de IEL/CNA/SEBRAE (2000) e Silva (2001), este método empírico baseou-se na utilização desse enfoque metodológico de busca de informações, associado ao uso intensivo de informações de fontes secundárias.

Os dados e as informações necessárias para a realização deste estudo foram obtidos em diferentes fontes, como: livros, revistas, teses e material disponível na internet, em "sites" de renome na área florestal e ambiental. Cada um dos autores pesquisou sobre determinado assunto dentro do tema central, e, posteriormente, efetivaram-se reuniões onde os conhecimentos adquiridos separadamente foram compartilhados pelos mesmos. Após intensas discussões, o trabalho foi sendo aprimorado através das diversificadas opiniões dos autores. Finalmente, foi escrito sob a forma de artigo.

\section{RESULTADOS E DISCUSSÃO}

\subsection{Características de mercado}

A cadeia agroindustrial da borracha natural é composta por quatro segmentos: i) segmentos de insumos e serviços, que envolve máquinas e equipamentos e assistência técnica; ii) segmento produtivo, envolvendo produção e extração de látex virgem, e beneficiamento da borracha; iii) segmento consumidor, que é a indústria pesada (pneumáticos) e indústria leve (artefatos); e, iv) segmento distribuidor, que são os varejistas (de pneus e artefatos) recauchutagens e borracharias (BORRACHA NATURAL, 2011).

O Brasil tornou-se o maior produtor mundial da borracha natural e passou a abastecer o comércio internacional de 1879 a 1912. Isso trouxe riqueza e desenvolvimento para cidades como Manaus, Belém e Rio Branco, na época e ainda foi responsável pela colonização do Acre, então território da Bolívia, que mais tarde foi anexado ao Brasil (LEÃO, 2000). Entretanto, a partir de 1912, as exportações brasileiras foram substituídas continuamente, até serem paralisadas no final dos anos 40 (PEREIRA et al., 2000).
O fim do ciclo da borracha iniciou em 1876 quando Henry Wickham levou para Inglaterra 70 mil mudas de seringueira onde apresentaram notável desenvolvimento. Neste mesmo período, 2.000 mudas foram levadas para Malásia onde também conseguiram se desenvolver. Em 1913, as seringueiras malaias superavam a produção do Brasil: 47.000 toneladas contra 37.000 mil toneladas (LEÃO, 2000).

Cerca de $70 \%$ de toda borracha natural consumida no mundo é destinada à produção de pneus, para os mais diferentes usos. As empresas pneumáticas são constituídas por grandes conglomerados econômicos que tem poder de pressão na formulação dos preços de compra. Já os países produtores dependem da comercialização desse produto, pois são economias subdesenvolvidas ou em desenvolvimento. Isso faz com que os preços, na maioria dos casos, fiquem ao sabor das políticas dos compradores, e, até recentemente, a consequência natural era que os preços sempre estavam desfavoráveis para os produtores (CONAB, 2003).

Nos 10 anos compreendidos entre 1992 e 2002, o Brasil despendeu US\$1,082 bilhão com importações de borracha natural nas suas diversas formas. No mesmo período, a produção brasileira de borracha natural totalizou $693,5 \mathrm{mil}$ toneladas, o que correspondeu a $36 \%$ do total consumido pelo País. Essa participação foi crescente no período, tendo atingido mais de $45 \%$ em alguns anos devido, especialmente, aos 45.000 hectares plantados por cerca de 2.500 produtores paulistas (CIFlorestas, 2011d).

Dados referentes ao ano de 2003 mostram que a produção brasileira de borracha natural estava em nono lugar na produção mundial, mesmo este sendo o berço da árvore produtora desta matéria prima, tendo a Tailândia e a Indonésia líderes deste mercado de 1999 a 2003. Vários fatores contribuíram para o sucesso da produção de borracha natural nos países asiáticos (CONAB, 2003).

Segundo informação de sites especializados, 70\% da borracha consumida no país é proveniente da Ásia, o que representa um gasto diário de $\mathrm{R} \$$ 3,6 milhões. O preço da borracha natural está em torno de R\$3,00, o quilo, um preço considerado excelente por analistas deste assunto. O Espírito Santo contribui com cerca de $6 \%$ da produção nacional, o que representa 107 mil toneladas de borracha, plantadas em 13 mil hectares. Mais de 60\% do território do município é composto por áreas rurais, mas somente uma pequena parte está ocupada (SERINGUEIRA, 2011a).

Em 2004, a Região Sudeste respondeu por 60,9\% da produção nacional de borracha (látex coagulado), seguida pelas regiões Centro-Oeste (21,4\%), Nordeste (14,6\%), Norte $(2,6 \%)$ e Sul $(0,5 \%)$ (AGRIANUAL, 2007). Nessas 
regiões há mão-de-obra especializada; maior volume de capital para investimento em tecnologia; concentração da maioria das indústrias consumidoras de borracha natural, o que reduz os custos logísticos com o transporte da matéria-prima; e clima adequado para o cultivo da seringueira (BORRACHANATURAL, 2007).

O Brasil, que no início do século XX detinha o monopólio da produção mundial, hoje responde por apenas $1,2 \%$, não conseguindo suprir as necessidades do seu mercado interno. O consumo nacional de borracha natural em 2005 foi de 297.000 toneladas (peso seco). Sendo assim, o país importa grande parte da borracha natural que consome. As importações brasileiras em 2005 foram de 203.927 toneladas, o equivalente a 269.222 milhões de dólares (SOARES et al., 2007).

Em 2008 o país de origem e centro de maior diversidade genética da seringueira, importou $220.959 .374 \mathrm{~kg}$ de borracha natural, ou seja, aproximadamente $221 \mathrm{mil}$ toneladas. Além dessa quantidade, foram importados 22.748 .924 kg de látex, ou seja, aproximadamente 23 mil toneladas nesse mesmo ano (GOOGLE, 2011).

No final do ano de 2010 o preço médio da borracha natural em são Paulo estava de $\mathrm{R} \$$ 2,60 o quilo, havendo um aumento nos meses seguintes. Em janeiro de 2011 estava de 3,05 ( $\mathrm{R} \$ \mathrm{Kg}$ ) e em fevereiro do mesmo ano estava de $\mathrm{R} \$ 3,75$ o quilo (CIFlorestas, 2010; 2011C).

O ano de 2010 iniciou com chuvas intensas e frequentes nas principais regiões produtoras do Estado de São Paulo, maior produtor nacional, provocando a redução da oferta da matéria-prima (CIFlorestas, 2010). O aumento nos preços da borracha natural em São Paulo pode ser explicado por estas fortes e constantes chuvas que diminuíram a oferta do produto (CIFlorestas, 2011b).

As projeções do consumo da borracha natural mostram que vale a pena investir em novos seringais no Brasil. Até 2030, estima-se que a demanda nacional alcance um milhão de toneladas, sendo que a produção interna é cerca de 130 mil toneladas (CIFlorestas, 2011b).

Após um recorde de US\$ 5.750,00 por tonelada no dia 14 de fevereiro de 2011, as cotações de borracha natural iniciaram um movimento de queda na bolsa de Cingapura, atingindo o menor valor de $2011 \mathrm{em} 14$ de março, de US\$ 3.800,00 por tonelada. De acordo com Heiko Rossmann, diretor da Associação Paulista de Produtores de borracha (Apabor), o preço do Granulado Escuro Brasileiro (GEB-1) para o próximo bimestre - abr/mai, antes com expectativa de superar a casa de $\mathrm{R} \$ 10,00$ por quilo, agora deve se situar ao redor de $\mathrm{R} \$ 9,50$ por quilo, valor ligeiramente superior ao preço praticado no mercado paulista no bimestre fev/mar, de R\$ 9,29 por quilo (CIFlorestas, 2011C).

Tendo como fonte o Instituto de Economia Agrícola (IEA), o CIFlorestas realizou um levantamento mensal do preço da borracha natural $(\mathrm{R} \$ / \mathrm{Kg})$, sendo este mensalmente, desde o mês de agosto de 2002 ao mês de fevereiro de 2011. Podendo ser perceptível o aumento no valor da matéria-prima e a oscilação existente no início de 2009 ao início de 2010, tendo seu maior valor de 3,72 ( $R \$ / K g)$ em março de 2011 (figura 1 ).

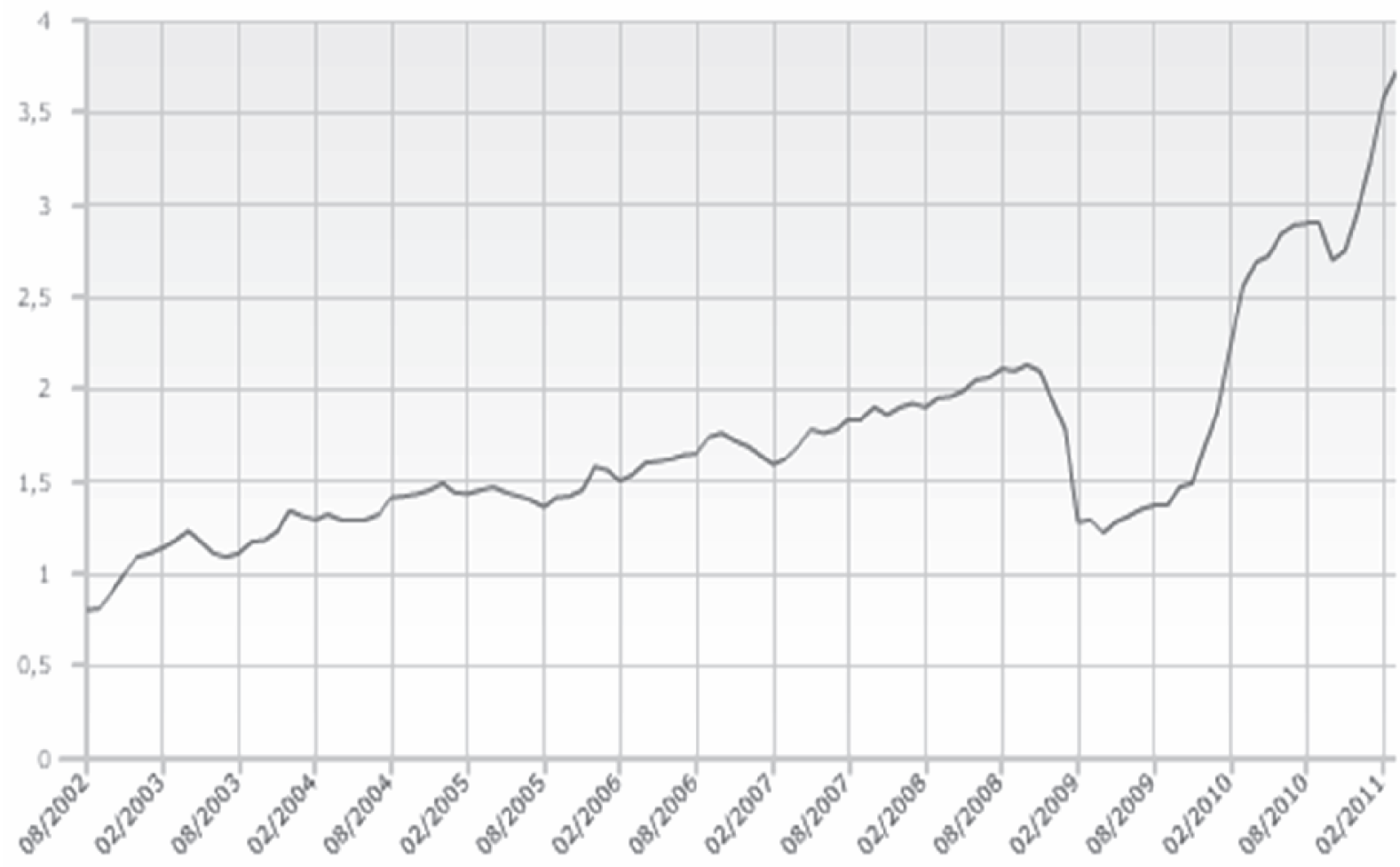

Figura 1: Oscilação de preço da borracha natural (R\$/Kg). 
3.2. Desafios na produção e comercialização do produto

No Brasil, os fatores que prejudicaram o desenvolvimento do cultivo da seringueira foram: o sistema de produção extrativista e a ausência de pesquisa para a solução dos problemas dos seringais da região amazônica. Deste modo, quase todas as tentativas de cultivo intensivo da seringueira nessa região fracassaram devido à incidência do fungo Microcyclus ulli (SOARES et al., 2007).

Entre as doenças que ocorrem na espécie, o "mal-dasfolhas", causada pelo fungo Microcylus ulei é uma das mais conhecidas e é o principal fator limitante à expansão da heiveicultura no Brasil, principalmente na região Norte do país. O dano maior é a queda prematura de folhas, podendo levar as plantas à morte. O controle pode ser realizado utilizando clones resistentes, área de escapes ou fungicidas. Além deste fungo existem outros que prejudicam o desenvolvimento desta espécie, atacando não somente as folhas como também as flores, frutos e sementes. $O$ ataque de pragas nestas espécies também já foi verificado (CIFlorestas, 2011a).

Apesar dos desafios da heveicultura no Brasil, ela está se estabelecendo como uma atividade lucrativa, conforme observou Nish et al. (2005), Cotta et al. (2006) e Soares et al. (2006). A produção brasileira de borracha natural voltou a crescer quando a seringueira começou ser cultivada fora da Amazônia, mais especificamente em regiões em que não há o fungo Microcyclus ulli.

A chuva em excesso atrapalha a produção porque o trabalho não pode ser feito. O corte no caule da seringueira é necessário para que a seiva escorra. Sem ele não é possível a extração do látex. Segundo os produtores, com a chuva a casca da seringueira fica úmida, o que dificulta a sangria. Além disso, o recipiente onde cai o látex enche de água e o produto é perdido (SERINGUEIRA, 2011b).

\section{Conclusão}

A cadeia produtiva da borracha natural gera emprego nas várias fases de produção: na colheita dos produtos, no transporte até as usinas de beneficiamento, nas usinas propriamente ditas, nas fábricas de pneumáticos, luvas cirúrgicas e preservativas. Essa característica de sistema de produção com grande geração de emprego e renda no campo e na cidade é importante para o cumprimento de exigências da ISO social, uma nova abordagem sobre as empresas que terão que adequar sua produção à responsabilidade social (Borracha Natural, 2011).

A cada 6 ha de floresta de seringueira em produção, com estande normal de árvores, um emprego direto e bem remunerado é gerado no campo. Sendo assim, a área colhida de seringueira em 2007 (114.842 ha) gerou no Brasil 19.140 empregos diretos, considerando o rendimento de mil árvores sangradas por dia/trabalhador, estimativa bastante conservadora. Em São Paulo, a renda mensal de um prestador de serviço de sangria era, em novembro de 2008, R\$3.500,00 (Borracha Natural, 2011).

A adoção de medidas governamentais que incentivassem o plantio da espécie que produz o látex seria atrativa para as pessoas que o extraem da floresta de forma extrativista, pois seria um incentivo para a formação de cooperativas, e a adoção de plantios de seringueira de forma planejada.

Investir em pesquisas que combatam ou que venham a reduzir a incidência de pragas e doenças que atacam os seringais seria de fundamental importância para o controle destes plantios, bem como garantir qualidade e quantidade suficiente para atender o mercado consumidor.

\section{Referências bibliográficas}

ANIP. Associação Nacional da Industria de Pneumáticos. 2009. http://www.anip.com.br.

BEGA, R.M. Heveicultura: alternativa para o pequeno proprietário rural no noroeste paulista. 2004. 88p. Monografia (Especialização em Gestão do Agronegócio) Universidade Federal de Viçosa.

BERNARDES, M.S.; VEIGA, A.S.; FONSECA FILHO, H. Mercado brasileiro de borracha natural. In: BERNARDES, M. S. (Ed.). Sangria da seringueira. Piracicaba: Esalq, 2000, p. 365-388.

BORRACHA NATURAL BRASILEIRA. 2011. Borracha Natural. http://www.borrachanatural.agr.br/ borrachanatural.php.

BORRACHA NATURAL BRASILEIRA. 2007 Borracha Natural. http://www.borrachanatural.agr.br/ borrachanatural.php.

CIFlorestas. CENTRO DE INTELIGÊNCIA EM FLORESTAS. $2011 a$.

http://www.ciflorestas.com.br/texto.php?p=seringueira.

CIFlorestas. CENTRO DE INTELIGÊNCIA EM FLORESTAS. 2011d. http://www.ciflorestas.com.br. 
CIFlorestas. CENTRO DE INTELIGÊNCIA EM FLORESTAS. 2010. Fatores que impactam o setor florestal em 2010. dezembro,

CIFlorestas. CENTRO DE INTELIGÊNCIA EM FLORESTAS. 2011b. Perspectiva dos negócios florestais em 2011. Fevereiro.

CIFlorestas. CENTRO DE INTELIGÊNCIA EM FLORESTAS. 2011c. Possíveis impactos das medidas governamentais de desaceleração da economia no setor florestal brasileiro. Março.

COTTA, M.K.; JACOVINE, L.A.G.; VALVERDE, S.R.; PAIVA, H.N.; VIRGENS FILHO, A.C.; SILVA, M.L. Análise econômica do consórcio seringueira-cacau para geração de certificados de emissões reduzidas. Revista Árvore, Viçosa, v.30, n.6, p. 969-979, 2006.

GONÇALVES, P. de S; CARDOSO, M.; COLOMBO, C.C.; ORTOLANI, A.A.; MARTINS, A.L.M.; SANTOS, I.C.I. Variabilidade genética da produção anual da seringueira: estimativas de parâmetros genéticos e estudo de interação genótipo $\mathrm{x}$ ambiente. Bragantia, Campinas, v.49, n.2, p.305-320, 1990.

GOOGLE. 2011. http://www.google.com.br |\#q=comercio+de+borracha+natural.

INSTITUTO EUVALDO LODI-IEL; CONFEDERAÇÃO NACIONAL DA AGRICULTURA-CNA; SERVIÇO BRASILEIRO DE APOIO ÀS MICRO E PEQUENAS EMPRESAS-SEBRAE. Estudo sobre a eficiência econômica e competitividade da cadeia agroindustrial da pecuária de corte no Brasil. Brasília: IEL/CNA/SEBRAE, 2000.403p.

LEÃO, R.M.A. Floresta e o Homem. São Paulo. Editora da Universidade de São Paulo: Instituto de Pesquisa e Estudos Florestais. 448 p. 2000.

MORENO, R.M.B.; FERREIRA, M.; GONÇALVES, P. de S.; MATTOSO, L.H.C. Avaliação do látex e da borracha natural de clones de seringueira no Estado de São Paulo. Pesquisa Agropecuária Brasileira, Brasília, v.38, n.5, p.583-590, 2003.

NISHI, M.H.; JACOVINE, L.A.G.; SILVA, M.L. da; VALVERDE, S.R.; NOGUEIRA, H.P.; ALVARENGA, A.P. Influência dos créditos de carbono na viabilidade financeira de três projetos florestais. Revista Árvore, Viçosa, v.29, n.2, p.263270, 2005
PEREIRA, J.P; DORETTO, M.; LEAL, A.C.; CASTRO, A.M.G.; RUCKER, N.A. Cadeia produtiva da borracha natural: análise diagnóstica e demandas atuais no Paraná. Londrina: IAPAR, 85 p. 2000.

SERINGUEIRA. 2011b. Especialista prevê que se o Brasil se tornar autossuficiente no produto até 2030 surgirão mais de 200 mil empregos no setor.

http://www.seringueira.com/artigos/?p=446.

SERINGUEIRA. 2011a. Serra Investe na Produção de Borracha Natural.

http://www.seringueira.com/artigos/?p=446.

SOARES, N.S.; SILVA, M.L.; JACOVINE, L.A.G.; NOCE, R. Aspectos técnicos e sociais da heveicultura e viabilidade econômica. In: ALVARENGA, A.P.; ROSADO, P.L.; CARMO, C. A.F.S.;TÔSTO, S.G. Seringueira: aspectos econômicos sociais e perspectiva para o seu fortalecimento.Viçosa, 2006. Cap.8, p. 141-163.

SOARES, N.S.; VALVERDE, S.R.; SILVA, M.L.; CAMPOS, A.C.; BRAGA, M.J. Demanda Brasileira de Importação de Borracha Natural, 1965 - 2005. Londrina: Sociedade Brasileira de Economia, Administração e Sociologia Rural. 22 a 25 de julho. 2007.

UFSC. UNIVERSIDADE FEDERAL DE SANTA CATARINA. 2011.

http://www.ced.ufsc.br/emt/trabalhos/borracha/borrach a/natural_arquivos/caracter.htm. 